УДК 338.1:[622+669]

Каренов Р. С.,

доктор эконом. наук, академик

Акыбаева Г. С.,

канд. эконом. наук, дочент

Карагандинский государственный университет имени академика Е. А. Букетова,

Республика Казахстан

\title{
ЕКОНОМІЧНІ ЧИННИКИ І ПЕРЕДУМОВИ СТАЛОГО РОЗВИТКУ ГІРНИЧО-МЕТАЛУРГІЙНОГО КОМПЛЕКСУ КАЗАХСТАНУ В ПРОГНОЗОВАНІЙ ПЕРСПЕКТИВІ
}

\section{ЭКОНОМИЧЕСКИЕ УСЛОВИЯ И ПРЕДПОСЫЛКИ УСТОЙЧИВОГО РАЗВИТИЯ ГОРНО-МЕТАЛЛУРГИЧЕСКОГО КОМПЛЕКСА КАЗАХСТАНА В ПРОГНОЗИРУЕМОЙ ПЕРСПЕКТИВЕ}

\section{ECONOMIC CONDITIONS AND PREREQUISITE FOR SUSTAINABLE DEVELOPMENT OF MINING AND METALLURGICAL COMPLEX OF KAZAKHSTAN IN THE FORESEEABLE FUTURE}

У статті визначено стратегічні напрямки розвитку гірничо-металургійного комплексу Казахстану, проведено узагальнення викликів, які будуть визначати конкурентоспроможність $i$ стійкість розвитку галузі в найближсчій (до 2030 p) $i$ довгостроковій (до 2050 г.) перспективі. Проведено аналіз стану свинщево-цинкової промисловості, визначено тендениії світового попиту $i$ пропозиції в цзьому контексті, аргументовано актуальність підвищення конкурентоспроможності галузі. Визначено об'єктивні причини консерватизму свиниевого виробництва, а також розглянуто нову технологію виплавки свиниюю. Проаналізовано позицію Республіки Казахстан на світовому ринку міді, представлено структуру світового споживання міді по галузях, визначено фактори, що підвищують рівень конкурентоспроможності изього металу. Дано оцінку стану мінерально-сировинної бази алюмінієвої промисловості світу $i$ Казахстану. Запропоновано продовжити геологорозвідувальні роботи з пошуку родовищ якісних бокситів і боксітоносних районів Казахстану в якості умови для забезпечення вітчизняних металургів надійною та стійкою матеріально-сировинною базою.

Ключові слова: сталий розвиток, гірничо-металургійний комплекс, конкурентоспроможність галузі, мінерально-сировинна база

В статье определены стратегические направления устойчивого развития горнометаллургического комплекса Казахстана, проведено обобщение вызовов, которые будут определять конкурентоспособность и устойчивость развития отрасли в ближайшей (до 2030 г.) и долгосрочной (до 2050 г.) перспективе. Проведен анализ состояния свиниовоцинковой промышленности, определены тенденции мирового спроса и предложения в этом контексте, аргументирована актуальность повышения конкурентоспособности отрасли. Определень объективные причинь консерватизма свинцового производства, а также рассмотрена новая технология выплавки свинца. Проанализирована позиция Республики Казахстан на мировом рынке меди, представлена структура мирового потребления меди по отраслям, определены факторы, повышающие уровень конкурентоспособности этого 
металла. Дана оиенка состоянию минерально-сырьевой базы алюминиевой промышленности мира и Казахстана. Предложено продолэить геологоразведочные работы по поиску месторождений качественных бокситов и бокситоносных районов Казахстана в качестве условия для обеспечения отечественных металлургов надежной и устойчивой материально-сырьевой базой.

Ключевые слова: устойчивое развитие, горно-металлургический комплекс, конкурентоспособность отрасли, минерально-сырьевая база

The article defines the strategic directions of sustainable development of mining and metallurgical complex of Kazakhstan, and generalizes challenges that will determine the competitiveness and sustainability of the industry in the short (up to 2030) and long (up to 2050) future. The article analyses the state of lead and zinc industry, identified trends in world supply and demand in this context. Authors show arguments of the relevance of increasing the competitiveness of the industry. There are defined objective reasons of conservatism of lead production, and considered new technology of smelting of lead. The study analyses the position of Kazakhstan on the world market of copper, presents the structure of world copper consumption by industry, as well as defines factors enhancing the competitiveness of this metal. Authors give the assessment of the state of mineral resources of the world aluminium industry and in Kazakhstan. There is supposed a continue of exploration work on search quality bauxite deposits and rich-inboksit regions of Kazakhstan, as a condition for providing domestic steelmakers with reliable and stable mineral and resources base.

Keywords: sustainable development, mining and metallurgical complex, competitiveness of the industry, mineral and resource base

Введение. Глобальные вызовы и стратегия развития горнометаллургического комплекса Казахстана. Горно-металлургический комплекс (ГМК) остается одним из ключевых секторов экономики Республики Казахстан (РК). На его долю приходится около 19 \% ВВП. На предприятиях отрасли работают 300 тыс. человек. В условиях вызовов последнего времени, связанных с ухудшением ситуации на мировых рынках металлов, сокращением экспортных поставок, волатильностью курсов валют, Правительство РК делает все возможное, чтобы помочь сохранить конкурентоспособность отечественной металлургической продукции. Так, в первой пятилетке форсированного индустриально-инновационного развития РК (2010-2014 гг.) в ГМК введены в эксплуатацию 60 новых производств на сумму 2,5 млрд. долл. США, создано свыше 16 тысяч постоянных рабочих мест [1;54].

В последние годы данной проблемой активно занимались следующие ученые стран СНГ: Астахов А. С., Ракишев Б. Р., Алшанов Р. А., Тот В., Герасимчук В. Г., Каренов Р. С., Кошанов А. К. и др. Актуальной остается тематика устойчивого развития стратегически важных отраслей экономики, в частности горно-металлургического комплекса как источника конкурентных преимуществ Казахстана на мировом рынке сырья и готовой продукции.

Постановка задачи. Целью исследования является решение таких задач: 
- определить стратегические направления устойчивого развития горнометаллургического комплекса Казахстана;

- проанализировать состояние свинцово-цинковой промышленности, а также тенденции мирового спроса и предложения в этом контексте;

- обозначить позицию Республики Казахстан на мировом рынке меди;

- выполнить оценку состояния минерально-сырьевой базы алюминиевой промышленности мира и Казахстана.

Методология. Результаты исследования получены с применением специальных статистических методов, а также общенаучных методов логического обобщения, научного сравнения, синтеза, анализа. Информационной базой исследования являются труды ученых, посвященные исследованию вопросов устойчивого развития экономических систем, в частности стратегического развития отраслевой экономики.

Результаты исследования. Дальнейшая политика государства в сфере ГМК будет взаимоувязанна с Программой индустриально-инновационного развития на 2015-2019 гг., в которой черная и цветная металлургия оставлены в качестве приоритетных направлений.

В рамках Комплексного плана по развитию горно-металлургической промышленности РК на 2014-2018 гг. предусмотрена реализация 27 инвестиционных проектов в этой сфере на общую сумму более 7 млрд. долл. США, которые должны быть запущены недропользователями за счет собственных и заемных средств. На сегодняшний день уже реализованы 4 проекта: по развитию рудных тел на нижних горизонтах Тишинского рудника (ТОО «Казцинк»), строительству золотоизвлекательной фабрики мощностью 2,4 т катодного золота в год (АО «АК «Алтыналмас») и Таскоринской золотоизвлекательной фабрики (ТОО «Таскара»), а также по добыче и переработке до 450 тыс. т золотосодержащей руды с получением сплава Доре в городе Житикара (ТОО «Брендт»). Объем инвестиций по этим проектам в 2014-2015 гг. составил около 122 млн. долл. [1; 55].

Говоря о наиболее значимых проектах, осуществляемых сейчас, можно особо отметить строительство Актогайского и Бозшакольского ГОКов, модернизацию технологий отработки Жезказганской группы медных месторождений, освоение полиметаллических руд месторождения «Шалкия», полиметаллических руд месторождения «Алайгыр», а также железорудного месторождения «Масальское». Все они ориентированы на внедрение современных технологий и максимальную эффективность производства».

Среди глобальных вызовов, которые в перспективе будут определять конкурентоспособность и устойчивость развития ГМК РК, можно назвать следующие [2; 76]:

- устойчивый рост потребности в высокотехнологичной и наукоемкой продукции ГМК; 
- снижение уровня прямого потребления чистых металлов и переход к использованию сплавов и композитных материалов;

- повышение экологических требований к промышленному производству и переход к «зеленой экономике»;

- тенденция роста применения нанотехнологий в процессах добычи и переработки минерального сырья;

- модернизация и применение более высоких технологий в геологоразведочных работах;

- ужесточение конкуренции на мировых товарных рынках;

- замедление темпов развития глобальной экономики, затянувшийся кризис в Еврозоне и спад в Китае;

- снижение мирового спроса со стороны металлопотребляющих отраслей (строительной и автомобильной), закрытие профицитных мощностей в металлургии Евросоюза;

- проблема металлургического перепроизводства в США, Европе и Китае.

Исходя из вышеуказанных глобальных вызовов, в ближайщей (до 2030 г.) и долгосрочной перспективе (до 2050 г.) одной из основных целей РК должно стать создание высокотехнологичного и устойчиво развивающегося индустриального горнодобывающего и металлургического комплексов национальной экономики, представляющего собой целостную многоотраслевую и многоуровневую систему научных, образовательных, инновационных, производственных, управленческих и консалтинговых структур. При этом жизненно важным условием устойчивого и эффективного развития ГМК РК в ожидаемой перспективе могут стать масштабные меры по развитию его минерально-сырьевой базы (МСБ).

\section{Современное состояние и перспективы развития свинцово-} цинковой промышленности. Анализ новых тенденций на мировом рынке продукции свинцово-цинковой промышленности показывает в последние годы потребление цинка и свинца в мире превосходит их производство. Стремительно растут цены на эти металлы, что вызвано возобновлением экономического подъема в Западных странах, а также изъятием из рынка избыточных производственных мощностей. Такая ситуация на рынке цветных металлов стимулирует развитие предприятий, производящих свинец и цинк $[3 ; 105]$.

В Казахстане основные запасы полиметаллов (категории $\mathrm{A}+\mathrm{B}+\mathrm{C}_{1}$ ) сегодня приходятся из АО «Жайремский ГОК» (34\% по свинцу и $22 \%$ по цинку), ТОО «Казцинк» (16\% и 25 \%), ТОО «Корпорация «Казахмыс» (по 14 $\%)$, ТОО «Шалкия Цинк ЛТД» (12\% и 19\%), а также АО «НК «СПК «Сарыарка» (9\% и 4\%). Недропользование полиметаллов осуществляется на 
30 объектах, из них на 19 ведется добыча, на 2 - разведка и на 9 совмещенная разведка и добыча [4; 37-38].

В ближайшие годы развитие минерально-сырьевой базы полиметаллов будет связано с освоением в Южном Казахстане крупного месторождения Шалкия, где предусматривается строительство нового цинкового завода. Кроме того, в Северном Казахстане запланирован ввод в эксплуатацию нетрадиционного для нашей страны и уникального по содержанию цинка месторождения карстового типа Шаймерден, а в Восточной Казахстане строительство рудников на базе месторождений Новолениногорское, Долинное и Обручевское.

В настоящее время продукция свинцово-цинковой промышленности Казахстана практически в полном объеме направляется на экспорт. Поэтому особенно актуальным является повышение ее конкурентоспособности. Решение этой задачи невозможно без надежного аналитического контроля, от эффективности которого зависит работа металлургических предприятий. Качественный и экспрессный контроль предотвращает использование и выпуск продукции, не соответствующей нормативным требованиям, позволяет более эффективно использовать ресурсы, снизить затраты на производство и сократить время производственного цикла [5; 44].

В будущем потребление свинца, устойчиво растущее в течение ряда лет в Азии в отличие от Северной Америки и Западной Европы за счет таких стран, как Республика Корея, Таиланд, Малайзия и КНР, должно учитываться в экспортной политике Казахстана. Получая дивиденды, налоги и т.д. от иностранных компаний, ставших экспортерами, необходимо совместно с ними продвигать свинцовый товар на мировые рынки.

По прогнозам, в последующие годы в Центральной и Восточной Европе, Латинской Америке, КНР и Юго-Восточной Азии спрос на свинец будет повышаться, что связано с расширением производства свинцово-кислотных аккумуляторов в условиях высокого роста продаж автомобилей. Особенно важно учесть рост спроса на свинцовые аккумуляторы на рынках ЮгоВосточной Азии и КНР и направить усилия на увеличение их производства в республике и повышение конкурентоспособности.

Для создания высококонкурентной отрасли в Казахстане имеются все условия - действующие предприятия, развитая свинцовая индустрия, научный и кадровый потенциал.

В ближайшие годы перспективы мировой цинковой промышленности оцениваются как довольно благоприятные. С учетом увеличения спроса на оцинкованную сталь в автомобилестроении, расширения сферы применения изделий из нее в жилищном строительстве, возрастания важности этого металла для промышленности любой развитой страны при улучшении 
мировой общехозяйственной конъюнктуры можно предполагать дальнейший рост спроса на рафинированный цинк.

Сегодня Казахстан является активным участником мировой торговли цинком. Основными импортерами казахстанского цинка являются США, Швейцария, Виргинские острова, Китай, Иран. США - один из крупнейших мировых потребителей цинка и изделий из него. Имеющиеся в стране производственные мощности не в состоянии обеспечить и одной трети потребности в этом металле, что усиливает зависимость американской экономики от импорта цинка, объемы которого ежегодно растут.

В настоящее время из производимых казахстанскими предприятиями металлов регистрации на ЛБМ (Лондонская биржа металлов) подлежат свинец рафинированный, цинк металлический, катодная медь, аффинированное золото и серебро. При этом в ЛБМ уже зарегистрированы: свинец АО «Казцинк» (сертификат NQ0550) и АО «Южполиметалл» (сертификат NQ0367). Золото и серебро (АО «Казцинк») зарегистрированы в Ассоциации драгоценных металлов в Лондоне [6;60].

Как известно, до сих пор большая часть первичного свинца в мире производится традиционным пирометаллургическим способом: «окислительный агломерирующий обжиг - восстановительная шахтная плавка». Такая ситуация может объясняться его высокой удельной производительностью, гибкостью но отношению к перерабатываемому сырью и хорошей отработанностью, несмотря на имеющиеся у него существенные недостатки [7; 40]:

1) потребность в 2-х агрегатах: агломашине для проведения окислительного обжига шихты и шахтной печи для восстановительной плавки агломерата;

2) низкая энергетическая эффективность процесса, обусловленная:

- большими потоками оборотных материалов на стадии окислительного обжига шихты;

- потерей тепла от горения сульфидов на стадии окислительного обжига шихты;

- затратами дорогостоящего металлургического кокса на проведение стадии восстановительной плавки охлажденного агломерата в шахтной печи;

- большими потоками технологических газов, обусловленных слабой герметизацией агрегатов, необходимостью большого избытка воздушного дутья и низкими, ввиду объективных ограничений, коэффициентами обогащения его кислородом;

3) несоответствие современным экологическим требованиям по эмиссиям свинца и других вредных веществ в атмосферу из-за:

- высокозатратной и недостаточно эффективной очистки больших потоков технологических газов; 
- выбросов в атмосферу больших объемов бедных сернистых газов окислительного обжига шихты, утилизация серы из которых экономически нерентабельна.

Сравнивая с медным производством, в котором традиционный процесс, также некогда доминировавший, практически себя изжил, можно полагать, что объективными причинами консерватизма свинцового производства являются:

- высокая капиталоемкость при относительно низкой рыночной стоимости металла;

- недостаточная эффективность природоохранного законодательства, допускающего использование традиционного способа производства свинца, несмотря на его общепризнанную экологическую опасность. Хотя надо отметить, что во многих странах, имеющих развитую металлургическую промышленность, санитарные нормы в последние годы стали более строгими, экологические требования ужесточились, увеличиваются штрафы за загрязнение окружающей среды.

Возможно, что именно по этой причине процесс модернизации этого самого консервативного металлургического производства все-таки идет. А в последнее десятилетие он заметно ускорился. Так, в связи с обострением энергетического кризиса и экологической ситуации стали появляться новые, энергетически более эффективные и экологически более чистые процессы прямой плавки свинцового сырья, начавшие постепенно вытеснять традиционный процесс. Уже к 1999 г. доля процессов прямой плавки первичного свинцового сырья оценочно составляла 20\%, а к настоящему времени выросла более чем вдвое и составляет около $45 \%$, благодаря масштабной модернизации металлургической промышленности Китая, являющегося ныне основным производителем свинца в мире.

Таким образом, учитывая отсутствие до сих пор экономически эффективных и промышленно отработанных гидрометаллургических технологий производства свинца, ближайшими перспективами развития свинцового производства является его модернизация на основе современных процессов прямой плавки, обладающих важными преимуществами с точки зрения энергоэффективности, ресурсосбережения и охраны окружающей среды. В мире в настоящее время промышленно используется несколько таких процессов: Kaldo (Швеция), QSL (Германия), TSL (Ausmelt и ISA Smelt, Австралия), КИВЦЭТ (Казахстан), SKS (Китай) и еще один, недавно разработанный и освоенный в Китае процесс прямой плавки в жидкой ванне с боковым дутьем (прототипом которого является хорошо известный в Казахстане процесс Ванюкова).

По мнению специалистов [7; 41], все разработанные к настоящему времени технологии прямой плавки свинцового сырья реализуют два основных способа организации процесса: 
1. Плавка сырья (как правило, гранулированного или кускового) в активно перемешиваемой (барботируемой) ванне расплава с использованием различных приемов введения в расплав кислородного или кислородновоздушного дутья (иначе, барботажная плавка или плавка в жидкой ванне). К процессам прямой плавки такого типа относятся QSL, TSL (Ausmelt/ISA Smelt), SKS (или плавка в жидкой ванне с донным кислородным дутьем) и плавка в жидкой ванне с боковым дутьем.

2. Плавка пылевидного сырья, подаваемого через горелки вместе с кислородным дутьем, осуществляемая во взвешенном состоянии (взвешенная или факельная плавка). К процессам такого типа относится КИВЦЭТ.

В области металлургии свинца существенных успехов добились ученые Национального центра по комплексной переработке минерального сырья (НЦ КПМС) РК. Речь идет как раз о создании новой технологии выплавки свинца методом кислородно-взвешенно-циклонно-электротермической (КИВЦЭТ) плавки. Ученые НЦ КПМС в течение последных двух десятилетий существенно модернизировали процесс и плавильный агрегат КИВЦЭТ для его внедрения на крупных свинцовых заводах мира. Новые технические решения защищены охранными документами ряда стран. В их числе патенты Казахстана и России, Австралии и Финляндии, Канады и стран ЕС, Китая и Бразилии, Мексики и Индии.

Авторами новой усовершенствованной технологии внесены принципиально новые решения, обеспечивающие более эффективные технологические операции. Предложены и промышленно освоены новые этапы технологии, которые заметно отличают модернизированный КИВЦЭТ от других процессов свинцовой плавки. На сегодня в мире по казахстанской модернизированной технологии КИВЦЭТ работают 4 установки общей производительностью 420 тыс. т свинца в год [8; 3].

Особо важно отметить то, что в условиях мировых тенденций истощения запасов качественного сырья и для нашей республики назревает вопрос переработки труднообогатимых свинцово-цинковых руд. Например, с месторождений Жайрем, Шалкия. В этом контексте использование модернизированной технологии технологии КИВЦЭТ представляется наиболее эффективным.

Медная промышленность республики на мировом рынке. Говоря о перспективах добычи медной руды, а также производства меди, следует сказать несколько слов об объемах ее природных запасов, которые оцениваются в пределах от 654 млн. до 1600 млн. т. При этом одной из главных современных проблем является старение 14 существующих старейших мировых рудников, содержащих 40\% мировых запасов меди. В недалеком будущем отсутствие достаточного количества разведанных и подтвержденных новых крупных месторождений, снижение резервов на 
старых месторождениях однозначно будут иметь влияние на рынок меди [9; 123-124].

Сегодня мировым производителем меди является Республика Чили. Она обладает самыми обширными запасами данного металла. На территории данного государства сосредоточено более 350 млн. т меди.

Чили располагает 28\% мировых запасов меди. Медная промышленность играет первостепенную роль в развитии экономики страны. Общий объем продукции горной промышленности Чили составляет около 8,5\% валового национального продукта и почти 50\% - чилийского экспорта [10; 70].

Чилийская государственная компания Corporacion Nacional del Cobre de Chile (Codelco) - крупнейшая по объемам производства меди не только в своей стране, но и в мире. В состав компании Codelco входят 6 производственных отделений, осуществляющих добычу и переработку медных руд: Коделько-Норте (Codelco Norte Division), Эль-Теньенте (El Teniente Division), Андина (Andina Division), Сальвадор (Salvador Division), Вентанас (Ventanas Division) и рудник Габи (Minera Gaby).

Чукикамата - огромное в мире месторождение медных руд в провинции Эль-Лао. Добывающий комплекс Чукикамата расположен в 1650 км к северу от столицы Чили, в высокогорных условиях с отметками 2840-2870 м выше уровня моря. Он включает два карьера: Чукикамата и Мина Сур (Mina Sur). Причем карьер Чукикамата - крупнейшее меднодобывающее предприятие в мире, производственной мощностью около 75 млн. т руды в год. Месторождение отрабатывается уступами высотой 15 м при коэффициенте вскрыши 2:1. Основное горное и транспортное оборудование: буровые станки, одноковшовые экскаваторы, одноковшовые колёсные погрузчики, бульдозеры, грейдеры, карьерные автосамосвалы. Первичное дробление руды осуществляется на внутрикарьерном комплексе. Руда из карьера поступает на обогатительную фабрику, где флотацией получают коллективный концентрат, который на молибденовом заводе разделяется на медный и молибденовый. Медный концентрат идёт на медеплавильный завод, где получают медь с чистотой 99,6\%. Последняя перерабатывается на рафинировочном заводе [10; 70-71].

Ожидание появления новых областей применения меди и прогнозы производителей в отношении развития рынка находят прямое отражение в объемах ввода новых мощностей. Структура мирового потребления меди по отраслям отражена в таблице. 
Структура мирового потребления меди по отраслям

\begin{tabular}{|l|l|l|}
\hline $\begin{array}{l}\text { № } \\
\text { ח/п }\end{array}$ & Отрасль мировой экономики & $\begin{array}{l}\text { Удельный вес в потреблении } \\
\text { меди, \% }\end{array}$ \\
\hline 1. & Строительство & 34 \\
\hline 2. & Электроэнергетика и электроника & 28 \\
\hline 3. & Машиностроение & 14 \\
\hline 4. & Транспорт & 12 \\
\hline 5. & Прочие & 12 \\
\hline \multicolumn{2}{|l}{ Примечание - данные работы [9; 125] } \\
\hline
\end{tabular}

Сейчас перед медной отраслью стоит главная задача - развитие рынка потребления и обеспечение его качественной востребованной продукцией. В мире основными потребителями меди являются строительство и высокотехнологичные отрасли промышленности. Использование меди в значительной степени зависит от темпов научно-технического прогресса и экономического развития страны. В США, например, около $50 \%$ всей продукции из меди и медных сплавов идет на нужды строительства, 21\% - на электронику и электротехнику. В Китае около $60 \%$ всей медной продукции идет на потребности энергетического комплекса. В Российской Федерации ежегодно потребляется около 3-4-тыс. т медных труб для тепло- и водоснабжения.

В настоящее время основными странами-потребителями медной продукции являются Китай, США, Япония, на которые приходится практически половина всей потребляемой медной продукции, хотя рафинированная медь используется в 70 странах мира. Именно экономический рост этих стран и потребность в металле на ближайшие годы оказывают сильное влияние на объемы производства меди.

В Казахстане производство меди является высокорентабельным бизнесом. Предприятия, построенные с ориентацией на местное сырье, всегда выдавали продукцию должного качества, казахстанская медь была эталоном качества. Благодаря стабильности качества продукции и надежности производства в медной индустрии относительно ранних, чем для других металлов, появились новые переделы по производству проката, кабельнопроводниковой продукции и эмальпровода.

Основной объем балансовых запасов и месторождений меди сосредоточен в Восточном и Центральном Казахстане. Резервом для укрепления минерально-сырьевой базы является ряд колчеданнополиметаллических месторождений на востоке республики (Артемьевское, Космурун, Акбастау и др.). Кроме того, в Центральном Казахстане подготовлено к эксплуатации меднопорфировое месторождение Нурказган с 
рудами высокого качества, в Южном Казахстане - Шатырколь, а в Жезказганском горнорудном районе - одно из крупнейших в стране месторождений Жаман-Айбат. Значительным потенциалом обладают такие месторождения меднопорфирового типа, как Актогай, Айдарлы, Коксай и Бозшакольское [4; 37].

Основной сырьевой базой ТОО «Казахмыс» по-прежнему остается Жезказганское месторождение. Между тем сегодня для Жезказганского региона стратегически важной является задача восполнения сырьевой базы. ПО «Жезказганцветмет» (ЖЦМ) - регионообразующее предприятие, от деятельности которого напрямую зависит дальнейшая судьба многих десятков тысяч работников предприятия и жителей региона. Именно поэтому предприятие прилагает все усилия, чтобы не допустить сокращения объемов производства.

Таким образом, наступил момент для оценки перспектив и разработки новой стратегии освоения Жезказганского месторождения, которая должна базироваться на проектировании устойчивой горнотехнической системы, реализация которой позволит не только продлить полноценную жизнь предприятия, но и вдохнуть новую жизнь в экономику региона.

В основе этой горнотехнической системы должен лежать полный цикл комплексного освоения недр, который предусматривает не только добычу и обогащение балансовых руд, но и вовлечение в добычу и глубокую переработку забалансовых руд, запасов, ранее списанных в потери, а также техногенного сырья (некондиционных руд, складируемых до настоящего времени в отвалах; отходов обогащения и др.) с обязательной утилизацией всех вновь образующихся отходов в выработанных пространствах карьеров и подземных рудников.

По мнению специалистов [11; 33], проектирование, формирование и функционирование горнотехнических систем на принципах устойчивого развития в течение всего жизненного цикла системы должно включать следующие критерии:

- потребление природных ресурсов в пределах их способности к восстановлению, если нет возможности замены на вторичные или иные ресурсы;

- минимизация/исключение выделения опасных или загрязняющих веществ в биосферу сверх их ассимилирующей способности;

- исключение образования отходов добычи и переработки руд путем реализации полного геотехнологического цикла освоения месторождений;

- исключение необратимых неблагоприятных воздействий на экосистемы, биогеохимические и гидрогеологические циклы;

- многофункциональность системы и (или) многократность ее эксплуатации на осваиваемом участке недр с приданием георесурсам новых 
полезных качеств;

- экономическая эффективность с достижением требуемых техникоэкономических показателей.

В целом комплексной подход к формированию стратегии дальнейшего освоения Жезказганского месторождения позволит решить не только технические и технологические, но и социальные, и экологические проблемы крупнейшего региона Казахстана, а именно [11; 34]:

- позволит стабилизировать геомеханическую ситуацию на месторождении;

- позволит существенно продлить срок службы предприятий, восполняя выбывающие производственные мощности по балансовым рудам при росте качественных показателей использования минеральных ресурсов недр;

- возможность маневрирования интенсивностью эксплуатации природных и техногенных минеральных ресурсов позволит поддерживать уровень экономической эффективности при более низких темпах разработки балансовых запасов;

- позволит обеспечить реализацию полного цикла комплексного освоения недр;

- позволит снизить негативное воздействие горных работ: на экологию региона.

Обобщая вышесказанное, можно сделать вывод, что продуценты и инвесторы видят благоприятные перспективы дальнейшего развития рынка меди в ряде стран мира и Казахстане.

Существует ряд причин, негативно влияющих на конкурентоспособность меди:

- снижение содержания основных компонентов в руде;

- увеличение стоимости энергетических ресурсов;

- ужесточение требований по охране окружающей среды, которое приводит к значительному росту соответствующих расходов у производителей;

- применение заменителей: например, алюминий вытесняет медь из производства электроэнергетических кабелей, электрооборудования, автомобильных радиаторов и рефрижераторных труб, титаном и сталью заменяют медь в теплообменниках, пластмассами — медный материал для производства водопроводных труб и оборудования.

Вместе с тем существуют и факторы, увеличивающие конкурентоспособность меди:

- появление новых технологий, направленных, например, на снижение затрат энергии, уменьшение вреда окружающей среде; разрабатываются более эффективные способы извлечения металла из рудного сырья; 
- возможность рециклинга медного лома и отходов;

- рост спроса на медь для таких отраслей, как производство строительных материалов, электронной техники, кабельно-проводниковой продукции, транспортных средств.

Таким образом, изменение экономической ситуации в самых крупных странах заметно отражается на объеме запасов металла на складах бирж мира и соответственно на уровне мировых цен на медь.

По-видимому, в течение ближайших лет сохранится экспортная ориентация казахстанских производителей меди. В дальнейшем медная отрасль должна развиваться как «сырьевая база» высокотехнологичных отраслей обрабатывающей промышленности. Этот путь оптимален для Казахстана, но требует принятия принципиальных изменений в законодательстве в инвестиционной, тарифной, инновационной областях и ряде других сфер.

Оценка состояния минерально-сырьевой базы алюминиевой промышленности мира и Казахстана. Основу минерально-сырьевой базы алюминиевой промышленности мира составляют месторождения бокситов, из которых вырабатывается глинозем - исходное сырье для получения металлического алюминия.

Крупнейшими обладателями запасов бокситов являются Австралия, Гвинея, Бразилия, Ямайка и Камерун - 46\% общих мировых и 58,3\% подтвержденных.

Казахстан по разведанным запасам бокситов занимает семнадцатое место в мире $(1,1 \%$ мировых запасов) и девятое по их добыче $[6 ; 86]$.

Основу МСБ алюминиевой промышленности РК формируют запасы трудноперерабатываемых бокситов Восточно-Торгайского бокситоносного района (месторождения Краснооктябрьское, Аятское и др.). Условия для получения глинозема из низкосортных бокситов данных месторождений были созданы благодаря внедрению новой технологической схемы, разработанной Павлодарским алюминиевым заводом. Перспективы дальнейшего развития сырьевой базы отечественной алюминиевой промышленности сегодня прежде всего связываются с нетрадиционными видами глиноземного сырья. Наибольший практический интерес могут представлять широко развитые на территории республики нефелин-лейцитовые и нефелиновые породы, а также алунитовые вторичные кварциты.

Львиная доля запасов бокситов, а это 93\%, сегодня приходится на КБРУ (Краснооктябрьское бокситовое рудоуправление) - подразделение АО «Алюминий Казахстана».

Оставшиеся 7\% делят пополам подразделения этой компании - ТБРУ (Торгайское бокситовое рудоуправление) и ТОО «Дидар». 
В настоящее время недропользование бокситов осуществляется на 5 объектах, из них на 4 идет добыча и на 1 - разведка [4; 38-40].

Сейчас в мировой практике алюминий широко применяется в электронике, машиностроении, авиастроении, строительной индустрии, как легирующая добавка, используется также в полупроводниковой технике. Очевидна экономическая выгода для Казахстана экспорта готовой алюминиевой продукции, а не только глинозема и боксита. Кроме того, следует отметить, что ежегодно республика импортирует большое количество изделий из алюминия.

Выводы. По результатам проведенного исследования решена важная научно-прикладная задача по определению экономических условий и предпосылок устойчивого развития горно-металлургического комплекса Казахстана в прогнозируемой перспективе.

Практическая значимость исследования заключается в том, что на основании решения поставленных задач, сформирован базис для принятия управленческих решений в области стратегического развития отрасли. Проведенный анализ факторов повышения конкурентоспособности меди как стратегически важного металла дает возможность определить основные направления совершенствования функционирования горно-металлургического комплекса Республики Казахстан. Поскольку металлургия оказалось в числе приоритетов индустриализации на ближайшие пять лет, задача номер один обеспечение отечественных металлургов надежной и устойчивой МСБ. В этой связи следует продолжить геологоразведочные работы по поиску месторождений качественных бокситов и бокситоносных районов Казахстана.

\section{Литература:}

1. Гахов С. Курс на контрцикличность // Kazahkstan. - 2015. - № 4. - С. 54-58.

2. Галиев С., Юсупова Л. Устойчивое развитие ГМК: проблемы и перспективы // Kazahkstan. - 2013. - № 3. - C. 76-80.

3. Куур Р. С., Еремеева О. В. Анализ новых тенденций на мировом рынке продукции свинцово-цинковой промышленности в условиях глобализации мирового хозяйства. - Усть-Каменгорск: ВНИИЦветмет, 2005. - 105 с.

4. Джантуреева Э. Недропользование 2000-2012: запасы, добыча, инвестиции // Kazahkstan. - 2013. - № 3. - С. 36-42.

5. Пелевина Н. Анализ продуктов цветной металлургии // Промышленность Казахстана. - 2012. - № 3 (72). - С. 44-45.

6. Муканов Д. Металлургия Казахстана: состояние, инновационный потенциал, тренд развития. - Алматы: РГП «НЦ КПМС РК», 2005. - 290 с.

7. Жарменов А., Ушаков Н., Шумский В. Технология КИВЦЭТ: создание и реализация // Промышленность Казахстана. - 2014. - № 2 (83). - С. 40-49.

8. Кожахметов С. Казахстанские инновации за рубежом // «Казахстанская правда», 30 июля 2015 года, С. 1 и С. 3. 
9. Якубов Н. М. Мировой рынок меди: состояние и перспективы развития // Маркетинг в России и за рубежом. - 2015. - № 4 (108). - С. 123-129.

10. Данилов Ю. Г. Чилийская государственная компания Codelco - крупнейшая горнодобывающая компания мира // Горная промышленность. - 2011. - № 5 (99). - С. 7072.

11. Рыльникова М. В., Юн А. Б., Терентьева И. В. Второе дыхание Жезказгана // Горная промышленность. - 2015. - № 3 (121). - С. 32-34. 